\title{
PERFIL DE GESTANTES E ACOMPANHANTES DAS OFICINAS PARA O PARTO ACOMPANHADO
}

\author{
Márcia de Almeida Santana1, Silvana Regina Rossi Kissula Souza², Dulce Maria Rosa Gualda², \\ Marilene Loewen Wall ${ }^{4}$
}

\begin{abstract}
RESUMO: Pesquisa exploratória e descritiva teve como objetivo identificar o perfil de participantes das oficinas do Projeto de Extensão Preparo para o parto acompanhado em uma maternidade escola de Curitiba-Paraná. A coleta de dados ocorreu de março a maio de 2010 com 53 gestantes e seus respectivos acompanhantes, a partir de um questionário semiestruturado sobre variáveis sociodemográficas, obstétricas e relativas ao parto acompanhado. Constatou-se que a maioria das gestantes era primípara, com ensino médio e idade entre 19 e 25 anos; as gestantes referiram necessidade de preparo e segurança para o parto, desejo do parto acompanhado pelo companheiro, mas desconheciam a lei do acompanhante. Percebe-se que os serviços de saúde pouco divulgam esse direito legal, sendo necessária a adoção de estratégias no pré-natal pela equipe de saúde e, principalmente, pelo enfermeiro, esclarecendo a mulher e familiares quanto ao seu direito. PALAVRAS-CHAVE: Parto humanizado; Cuidado pré-natal; Gestantes; Educação em saúde.

\section{A PROFILE OF MOTHERS-TO-BE AND THOSE ACCOMPANYING THEM IN ACCOMPANIED-BIRTH WORKSHOPS}

ABSTRACT: The exploratory and descriptive research was intended to shed light on the profile of participants in the workshops run as part of the preparation for accompanied birth extension project at a maternity school in the city of Curitiba in the state of Paraná. Data collection took place between March and May 2010 involving 53 pregnant women and the people accompanying them to the birth, via a semi-structured questionnaire on various factors including socio-demographic, obstetric and others related to accompanied birth. It was observed that the majority of the women were pregnant for the first time, educated to senior high school level and aged between 19 and 25; the pregnant women cited the necessity of preparation and safety for the birth and their desire for their partner to be present at the birth; they were unaware of the 'Law for Accompanied Birth', which gives women the right to have a companion present during birth. It is noted that this legal right is little-mentioned by the health services, it being necessary for health teams and particularly nurses to adopt strategies in the pre-natal phase for clarifying this right to women and their family members.

KEYWORDS: Humanized birth; Pre-natal care; Pregnant women; Health education.

\section{PERFIL DE GESTANTES Y ACOMPAÑANTES DE LOS CURSOS PARA EL PARTO ACOMPAÑADO}

RESUMEN: Investigación exploratoria y descriptiva tuvo como objetivo identificar el perfil de participantes de los cursos del Proyecto de Extensión Preparación para el parto acompañado en una maternidad escuela de Curitiba - Paraná. Los datos fueron recogidos de marzo a mayo de 2010 con 53 gestantes y sus respectivos acompañantes, a partir de un cuestionário semiestructurado sobre variables sociodemográficas, obstétricas y relativas al parto acompañado. Se constató que la mayoría de las gestantes era primípara, con nivel medio y edad entre 19 y 25 años; las gestantes mencionaron necesidad de preparación y seguridad para el parto, deseo del parto acompañado por el compañero, pero desconocían la ley del acompañante. Se puede percibir que los servicios de salud poco divulgan ese derecho legal, siendo necesaria la adopción de estrategias en el prenatal por el equipo de salud y, principalmente, por lo enfermero, aclarando a la mujer y familiares acerca de su derecho.

PALABRAS-CLAVE: Parto humanizado; Cuidado prenatal; Gestantes; Educación en salud.

*Artigo extraído dos resultados do Projeto de Extensão Universitária "Preparo para o parto acompanhado" e apresentado em dezembro de 2009 como Monografia de conclusão de curso ao Departamento de Enfermagem da Universidade Federal do Paraná - UFPR.

${ }^{1}$ Enfermeira. Especializando em Saúde Pública pelo Instituto Brasileiro de Pós-Graduação e Extensão.

${ }^{2}$ Enfermeira Obstétrica. Mestre em Engenharia da Produção. Professora do Curso de Graduação em Enfermagem da UFPR Doutoranda pelo Programa Interunidades de Enfermagem da Universidade de São Paulo - USP.

${ }^{3}$ Obstetriz. Doutora em Enfermagem. Professora do Departamento de Enfermagem Materno-infantil e Psiquiátrica da USP

${ }^{4}$ Enfermeira Obstétrica. Doutora em Enfermagem. Professora do Curso de Graduação e do Programa de Pós-Graduação em Enfermagem da UFPR. Diretora de Enfermagem do Hospital de Clínicas da UFPR.

Autor correspondente:

Silvana Regina Rossi Kissula Souza

Universidade Federal do Paraná

Av. Pref. Lothário Meissner, 632 - 80210-270 - Curitiba-PR-Brasil

E-mail: skissula@ufpr.br e skissula@usp.br
Recebido: 25/11/2011

Aprovado: 15/02/2012

Cogitare Enferm. 2012 Jan/Mar; 17(1):106-12 


\section{INTRODUÇÃO}

No transcorrer da história, o parto sempre foi considerado um acontecimento fisiológico natural, de âmbito doméstico, no qual a gestante, ao dar a luz, era acompanhada por membros do seu grupo social e, na maioria das vezes, assistida durante todo o trabalho de parto por uma parteira da comunidade ou alguém de sua confiança ${ }^{(1)}$.

Após a Segunda Guerra Mundial, em busca da redução das altas taxas de mortalidade das mães e crianças, o parto foi institucionalizado, ficando caracterizado o modelo biomédico de atenção ao parto. Apesar de recursos tecnológicos disponíveis e maior amparo médico à gestante a redução dos riscos e de complicações ou mortes no parto não foram tão visíveis, e o nascimento passou de um evento natural a ser medicalizado ${ }^{(2-3)}$.

Neste modelo medicalizado o parto é cercado de intervenções obstétricas e isto implicou no afastamento da mulher de seus familiares e na vivência do parto em um espaço institucional estranho, dominado por uma linguagem técnica e desconhecida, a mulher deixou de ser a figura mais importante no parto, tendo seus sentimentos e desejos ignorados ${ }^{(4)}$. Na busca de alterar esse panorama, iniciou-se, na década de 1980, um movimento internacional cuja proposta é resgatar a compreensão do nascimento como uma experiência natural que envolve aspectos biológicos, psicológicos e sociais da parturiente, compreendendo que a mulher em trabalho de parto deve receber suporte emocional e atenção à saúde com o mínimo de intervenções necessárias ${ }^{(5)}$.

Nesta visão e, de acordo com a política de humanização da saúde vigente no Brasil, a partir de lei n. 8.080, de 19 de setembro de 1990, o Ministério da Saúde (MS) endossou as determinações do Organização Mundial da Saúde (OMS) e lançou, em 2000, o Programa de Humanização no Pré Natal e Nascimento (PHPN), cujos objetivos são assegurar a melhoria do acesso, da cobertura e da qualidade do acompanhamento pré-natal, da assistência ao parto e puerpério às gestantes e ao recém-nascido ${ }^{(3)}$. Neste contexto, a OMS define, entre as estratégias de humanização do parto, que na assistência à parturiente deve-se permitir e respeitar o desejo da mulher de ter um acompanhante da família ou amigo durante o trabalho de parto e parto ${ }^{(6)}$. Esta orientação foi regulamentada no Brasil após abril de 2005, e é conhecida como lei do Acompanhante de Parto( lei n. 11.108) $)^{(7)}$.

Assim, tanto na visão da OMS, quanto do MS a participação de um acompanhante escolhido pela parturiente passou a ser reconhecida como um fator importante na promoção da saúde física e psíquica da parturiente ${ }^{(6-7)}$. Sua presença oportuniza apoio contínuo e contribui para amenizar a ansiedade e as sensações de angústia e medo. As parturientes que recebem apoio emocional no trabalho de parto e parto apresentam resultados perinatais mais positivos do que as que não recebem tal acompanhamento ${ }^{(1)}$.

Embora a participação de um acompanhante seja benéfica muitas mulheres não têm desfrutado desse direito. $\mathrm{O}$ desconhecimento ao direito legal e as limitações institucionais, como a falta de estrutura física, ausência de treinamento da equipe ou ausência de aceitação por alguns profissionais tem dificultado a efetiva observação dos dispositivos legais o exercício da lei ${ }^{(8)}$.

No Estado do Paraná, a capital Curitiba conta com o Programa Mãe Curitibana que é uma iniciativa com vistas a um bom encaminhamento da humanização do nascimento, do pré-natal ao puerpério; desde 2009 essa iniciativa tem estimulado a participação do pai acompanhando as consultas de pré-natal. Dessa forma o Programa, ao cadastrar a mulher no início do pré-natal, também determina em qual maternidade a mulher terá seu parto; o casal é convidado a visitar e conhecer a maternidade, com o intuito de fortalecer seu vínculo com o serviço e promover a ambiência ${ }^{(9)}$.

Mesmo diante desta iniciativa percebe-se uma lacuna na implementação da Lei do Acompanhante de parto em instituições hospitalares nesta realidade. Em 2008, observando a necessidade de maior divulgação do referido direito, e como compromisso social da Universidade Federal do Paraná com a população, foi formulado o Projeto de Extensão Universitária, intitulado "Preparo para o parto acompanhado". Este projeto, de cunho educativo, foi idealizado e implementado por professoras e acadêmicos do Curso de Graduação em Enfermagem da referida universidade com o objetivo de auxiliar gestantes e acompanhantes a conhecer e usufruir da lei, bem como informá-los sobre questões relacionadas ao parto normal, redução dos índices de cesareanas e encorajamento para o processo de nascimento humanizado.

Tendo em vista a procura das gestantes e seus acompanhantes para participação nas oficinas do referido projeto, bem como a existência de um dispositivo legal para a inserção de alguém da escolha da mulher no processo de nascimento, o presente estudo propõe realizar um diagnóstico situacional com o objetivo de identificar o perfil destas gestantes e de respectivos acompanhantes nas oficinas do referido projeto. 


\section{MÉTODO}

Trata-se de uma pesquisa exploratória e descritiva realizada em uma maternidade escola da capital paranaense, que é referência no atendimento ao parto às gestantes de baixo risco e adolescentes gestantes, cadastradas nas Unidades de Saúde do município pelo Programa Mãe Curitibana.

O estudo contou com 53 gestantes, e seus respectivos acompanhantes, os quais participaram das oficinas promovidas pelo Projeto de Extensão, no período de março a maio de 2010. Foram critérios de inclusão no estudo: ser gestantes no terceiro trimestre de gestação e participar das oficinas promovidas pelo projeto, independentemente de raça, paridade ou qualquer outro indicador que não mencionado anteriormente.

Os dados foram coletados na primeira oficina da qual a gestante e acompanhante participaram. As oficinas foram realizadas semanalmente no auditório da referida maternidade, sendo dois encontros por grupo; deste modo, cada casal (gestante e acompanhante) participou de duas oficinas. Antes do início das atividades do primeiro encontro, as gestantes maiores de 18 anos e menores acompanhadas por seus responsáveis foram orientadas sobre os objetivos do estudo e forma de coleta de dados, bem como sobre os preceitos éticos da pesquisa, ressaltando-se a liberdade em aceitar ou não participar. O conteúdo do Termo de Consentimento Livre e Esclarecido foi apresentado com recurso de multimídia e, após esclarecimentos, as gestantes que assentiram em participar assinaram o TCLE, observado-se a Resolução 196/96 ${ }^{(10)}$.

Para a coleta dos dados utilizou-se um instrumento semiestruturado, com questões fechadas para identificar variável sociodemográfica das participantes: idade materna, estado civil, escolaridade, ocupação, renda familiar, procedência e tipo de moradia; e antecedentes obstétricos: número de partos vaginal, cesáreos e abortos, idade gestacional, tipo de gravidez e número de consultas de pré-natal. As questões abertas se referiam ao tema, motivação e expectativas sobre o parto acompanhado e informações sobre o acompanhante escolhido pela gestante. Os dados foram agrupados em planilhas do software Excel, e os resultados foram analisados por meio de estatística descritiva simples.

O estudo foi aprovado pelo Comitê de Ética em Pesquisa do Setor de Ciências da Saúde da UFPR com registro CEP/SD: 888.013.10.02.

\section{RESULTADOS}

Quanto às características sociodemográficas das gestantes, 88,7\%(47) estavam da faixa etária entre 19 e 35 anos; 54,7\%(29) com idades entre 19 e 25 anos, $7,5 \%(4)$ de mães adolescentes, com idade inferior a 18 anos e apenas 3,8\%(2) com idade acima de 36 anos. A maioria (90,6\%), ou seja, 48 residentes em Curitiba; apenas 5 gestantes (menos de 1\%) eram procedentes de outros municípios.

Predominaram mulheres brancas, ou seja 84,9\%(45), enquanto que $13,2 \%$ (7) eram afro-descentes; uma participante $(1,9 \%)$ referiu ser indígena. Quanto à religião, $46 \%(25)$ das participantes eram católicas, 35,8\%(19) evangélicas, $5,7 \%(3)$ referiram outras religiões e $11,3 \%(6)$ referiram não ter religião. A renda familiar informada era inferior a um salário mínimo entre 3,8\%(2) participantes, a maioria, $83 \%(44)$, referiram renda entre um e quatro salários mínimos, 9,4\%(5) entre quatro e sete salários mínimos, e 3,8\%(2) referiram renda familiar acima de sete salários mínimos.

Em relação à escolaridade, 7,5\%(4) concluíram o ensino fundamental, enquanto $5,7 \%$ (3) cursaram entre a $1^{\mathrm{a}}$ e a $8^{\mathrm{a}}$ série, ou seja, possuíam ensino fundamental incompleto; $34 \%(18)$ referiram ter o ensino médio incompleto, $24,5 \%(13)$, ensino médio completo; $22,6 \%(12)$ ingressaram no ensino universitário, mas não o concluíram e apenas 5,7\%(3) completaram o curso superior. Os resultados referentes à ocupação demonstraram que 30,3\%(16) das participantes possuíam emprego formal, 17\%(9) eram autônomas, $35,8 \%(19)$ estavam desempregadas, $17 \%(9)$ referiram ser do lar ou estudantes. As principais ocupações referidas eram prestação de serviços, comércio, atividades administrativas, educação, saúde, empresarial e de comunicação.

Quanto à condição conjugal, 30,3\%(16) declararamse casadas, $45,2 \%(24)$ referiram união estável, 22,6\%(12) eram solteiras e 1,9\%(1) não respondeu. Em relação aos dados obstétricos, 69,8\%(37) eram primigestas; entre as multigestas, 30,2\%(16) tiveram parto vaginal. Quanto à presença do acompanhante, apenas 5,6\%(3) referiram acompanhante no parto anterior.

A maioria das participantes $(96,2 \% ; 51)$ referiu a não ocorrência de problemas gestacionais e 56,6\%(30) das participantes estavam com mais de 35 semanas de gestação. Em relação ao número de consultas de prénatal, observou-se 90,6\%(48) de frequência, apenas $9,4 \%(5)$ não realizaram as seis consultas mínimas preconizadas pelo MS. 
O desconhecimento da lei do acompanhante foi referido por $56,6 \%(30)$ das gestantes; entre as que referiram conhecer a lei, 82,6\%(19) delas conheceram em visita à maternidade pelo Programa Mãe Curitibana, 13,2\%(3) obtiveram a informação participando de palestras e oficinas nas unidades de saúde, e 4,4\%(1) por meio da mídia escrita. Em relação à pessoa de escolha como acompanhante, $81,2 \%(43)$, das gestantes escolheram o companheiro ou esposo, 7,5\%(4) a mãe, 9,4\%(5) outro familiar do sexo feminino (tia, sogra, irmã) e 1,9\%(1) escolheu uma amiga.

Em relação à faixa etária dos acompanhantes, $62,2 \%$ (33) encontravam-se na faixa etária de 22 a 35 anos, os mais jovens (idade entre 18 e 21 anos) representaram 18,9\%(10) da amostra e a mesma percentagem foi encontrada no grupo com mais de 36 anos. Quanto à escolaridade dos acompanhantes 5,7\%(3) cursaram o ensino fundamental completo e 5,7\%(3) não completaram o ensino fundamental; 43,4\%(23) completaram o ensino médio e 22,6\%(12) não o completaram; 11,3\%(6) referiram ter curso superior completo e 11,3\%(6) têm formação universitária incompleta. Em relação a ocupação $69,8 \%(37)$ referiam estar empregados (emprego formal), $22,7 \%(12)$ referiram trabalho autônomo e 7,5\%(4) referiram estar desempregados.

Os motivos que as gestantes referiram para a escolha do acompanhante foram afinidade, segurança, consideração, homenagem e atender o desejo do próprio acompanhante; mais de um motivo foi assinalado, com destaque para o motivo "segurança" (Gráfico 1).

Em relação ao conhecimento sobre as oficinas pro-

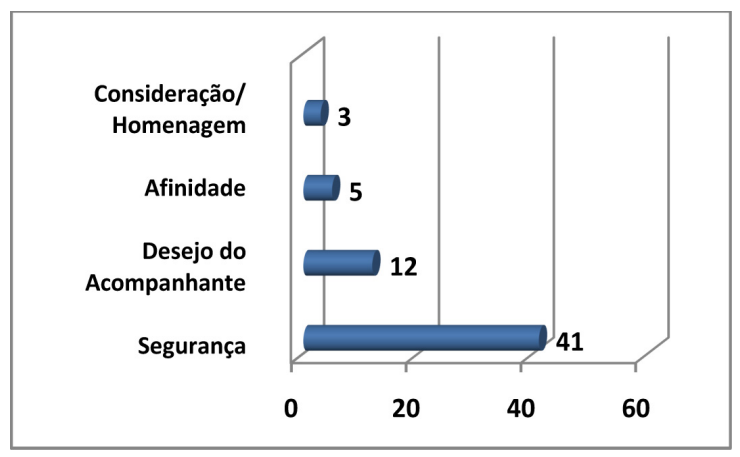

Gráfico 1 - Motivos da gestante para a escolha do acompanhante no parto. Curitiba 2010

movidas pelo Projeto de Extensão, 66\%(35) das participantes tiveram o acesso à informação durante visita do Programa Mãe Curitibana à maternidade, 11,3\%(6) por meio das Unidades Básicas de Saúde; 9,4\%(5) por indicação de amigos ou conhecidos, 5,7\%(3) por interesse e busca pessoal e 7,5\%(4) por outros moti- vos, tais como indicação da enfermeira, do médico e informação na carteira pré-natal. Entre os motivos de participação nas oficinas as participantes assinalaram mais de uma opção, porém o principal motivo foi o de obter permissão para entrada do acompanhante no momento do parto (Gráfico 2).

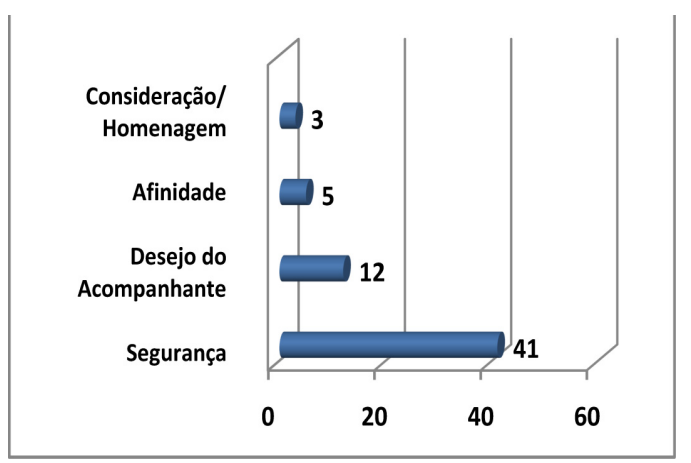

Gráfico 2- Motivos para a participação da gestante na oficina de oficinas para o parto acompanhado. Curitiba, 2010

\section{DISCUSSÃO}

A faixa etária predominante entre as participantes - entre 19 e 35 anos - é considerada pelo Ministério da Saúde como o ideal para gestação; segundo dados MS, $14,85 \%$ das mulheres que engravidaram e ganharam seus filhos em 2005 estavam na faixa etária de até 19 anos, e $75,15 \%$ das mulheres estavam na fase adulta ${ }^{(11)}$, dados que condizem com o resultado aqui apresentado.

Neste estudo a escolaridade de gestantes e acompanhantes teve predomínio no ensino médio e superior. Alguns estudos têm demonstrado que a mortalidade perinatal, neonatal e infantil está associada à baixa escolaridade materna e uma escolaridade materna maior, segundo o MS, sugere menor risco obstétrico na população estudada ${ }^{(7,12)}$. Quanto a condição conjugal observamos resultados similares à síntese dos indicadores sociais do IBGE para o ano de 2008, com maior proporção de mulheres auto declaradas casadas $(40,4 \%)$ e em união estável $(46,46 \%)^{(13)}$.

A OMS recomenda às gestantes a realização de pelo menos seis consultas de pré-natal durante a gestação; este acompanhamento permite identificar possíveis riscos à saúde da mulher - como diabetes e hipertensão arterial e repercussão de doenças no bebê $\hat{e}^{(14)}$. Em 2005, segundo o MS, a média brasileira de consultas prénatais foi de 5,45 consultas, apenas $25 \%$ das gestantes realizaram seis ou mais consultas ${ }^{(15)}$.

$\mathrm{O}$ desejo das gestantes de vivenciar o parto com um acompanhante de sua escolha também pode 
estar relacionado ao fato de que a maioria está vivenciando sua primeira gestação. A gravidez representa um momento único e especial para a mulher e sentimentos como medo, inseguranças e dúvidas afloram com mais intensidade, principalmente entre primigestas. Para elas, receber cuidado e conforto no momento do parto pode influenciar positivamente suas atitudes, sentimentos e percepção do momento vivido, oportunizando um melhor desenvolvimento no puerpério ${ }^{(5)}$.

Os resultados do estudo evidenciam que muitas participantes referiram desconhecer o dispositivo legal que lhes dá o direito de ter um acompanhante durante o parto, esses dados corroboram com estudo realizado em 2006 sobre o tema no qual identificou-se que $60 \%$ das gestantes desconheciam tal direito ${ }^{(12)}$. Esse desconhecimento, se analisado no âmbito dos direitos humanos, vai ao encontro a um dos mais violados direitos da saúde que é o direito à informação. Os profissionais de saúde são quem mais deveriam informar a gestante de seus direitos, entretanto não o fazem de maneira eficaz ou não o realizam. E, consequentemente, o direito à presença de um acompanhante durante o trabalho de parto e parto também é desrespeitado ${ }^{(12)}$. As redes de humanização ao parto, movimentos de mulheres, podem ter papel fundamental para garantir que estes direitos sejam respeitados em nossa sociedade. A lei do acompanhante pode ajudar as mulheres a exigirem mais para sua saúde, auxiliando em medidas de mudanças de atendimento, ao integrar abordagens baseadas em evidências científicas e direitos necessários para a dignidade dos cidadãos ${ }^{(16)}$.

Entre as mulheres que referiram conhecer a lei $\mathrm{n}$. 11.108 , a maioria tomou conhecimento desse dispositivo legal durante a visita à maternidade, atividade esta preconizada pelo Programa Mãe Curitibana, salientando-se a relevância do programa e objetivos deste. Também esse resultado revela que uma parcela das participantes tem buscado seus direitos na atenção à saúde, sendo beneficiada por seus princípios. $\mathrm{O}$ Programa da capital paranaense está em consonância com o PHPN apontando que a gestante deve ter assegurado o acesso à maternidade em que será atendida no momento do parto. O PHPN preconiza que "toda gestante tem direito ao acesso a atendimento digno e de qualidade"(17:6). O profissional enfermeiro é agente de transformação social e, como tal, seu trabalho deve se voltar para as práticas educativas, na compreensão de que formação, informação e orientação são aspectos inerentes ao cuidado em saúde. Na atenção humanizada à gestação, parto e nascimento, o enfermeiro deve exercer seu papel de educador. É o profissional de saúde que, desde o início do pré-natal até o pós-parto, tem maior contato com a futura mãe e, portanto, deve reunir esforços no sentido de estimular o parto acompanhado e garantir à gestante sua autonomia no processo da parturição.

As participantes deste estudo externaram a preferência pela companhia de seus companheiros para a vivência do nascimento do filho, refutando que gravidez, parto e maternidade são eventos exclusivos das mulheres, e na qual a participação dos homens não é permitida $^{(18)}$. A participação do pai no parto tem sido motivada pela nova vivência das mulheres na sociedade e sua inserção no mercado de trabalho. Os papeis desempenhados no lar não são mais atribuídos somente às mulheres, e os pais têm assumido, cada vez mais, os cuidados com os filhos; apresenta-se uma nova visão que compreende relações conjugais e familiares ${ }^{(1)}$. Os dados do presente estudo divergem dos encontrados em estudo realizado no ano de 2009 em estado do nordeste brasileiro e no qual a maioria dos acompanhantes foram mulheres (mãe, amiga, cunhada e sogra) ${ }^{(19)}$. O parto é um evento que envolve a sexualidade e ainda há mulheres que têm seus constructos culturais mais conservadores sobre intimidade, apoio emocional, privacidade e inibição, o que leva, possivelmente, a escolherem outras mulheres, por não considerarem a figura masculina parte de um momento tão íntimo de suas vidas ${ }^{(20)}$.

A escolha do acompanhante foi motivada por vários sentimentos, entretanto o motivo de segurança foi o mais mencionado. Há evidências de que o suporte durante o trabalho de parto gera resultados maternos benéfi$\cos ^{(3)}$; na percepção das parturientes o acompanhante é de grande ajuda, especialmente relacionada ao apoio emocional e conforto físico ${ }^{(4)}$.

Entre os motivos que levaram as gestantes a participar das oficinas do projeto o mais mencionado foi o de obter permissão para entrada do acompanhante no momento do parto, ou seja, tiveram a intenção de um apoio institucional para vivenciarem o processo de nascimento de seus filhos. É importante salientar que a participação nas oficinas não é obrigatória, e a confirmação de presença nas oficinas também não garante a participação do acompanhante no processo de nascimento. Contudo, ao participar das oficinas, as gestantes e acompanhantes recebem também informações do dispositivo legal e orientações, caso sejam negados aos participantes o direito ao parto acompanhado, o que tem auxiliado a instituição a promover o 
cumprimento da lei do acompanhante a garantir este direito aos cidadãos.

\section{CONSIDERAÇÕES FINAIS}

Este estudo possibilitou conhecer o perfil das gestantes que participaram do Projeto de Extensão Preparo para o Parto Acompanhado e refletir sobre a prática dos profissionais de saúde em defesa do parto humanizado. Os benefícios resultantes da presença do acompanhante no processo de gestação, parto e nascimento encontram amplo embasamento teórico na literatura. Entretanto, conhecer o perfil das mulheres e acompanhantes que desejam se beneficiar da Lei do Acompanhante é interessante, pois possibilita traçar estratégias para a melhoria das políticas públicas de humanização ao parto.

Tanto a literatura quanto os dados da pesquisa evidenciam que nem sempre o usuário da saúde conhece seus direitos. Este fato nos conduz à conclusão de que os serviços de saúde têm falhado, ainda que parcialmente, na divulgação da lei, seja por falta de interesse ou por falta de conhecimento. Assim, sugere-se uma discussão sobre o planejamento e implementação por parte da equipe de saúde, principalmente pelo profissional enfermeiro, de ações educativas no pré-natal que visem orientar e informar gestantes e seus familiares sobre seus direitos garantidos legalmente.

\section{REFERÊNCIAS}

1. Motta CCL, Crepaldi MA. O pai no parto e o apoio emocional: perspectiva da parturiente. Paidéia. 2005;15(30):105-18.

2. Brüggemann OM, Parpinelli MA, Osis MJD. Evidências sobre o suporte durante o trabalho de parto e parto: uma revisão da literatura. Cad. saude publica. 2005;21(5):1316-27.

3. Ministério da Saúde (BR). Parto, aborto e puerpério: assistência humanizada à mulher. Secretaria de Políticas Públicas. Área Técnica da Mulher. 2a ed. Brasília;2001.

4. Domingues RMSM, Santos EM, Leal MC. Aspectos da satisfação das mulheres com a assistência ao parto: contribuições para o debate. Cad. saude publica. 2004; 20 Suppl 1:S52-62.

5. Diniz CSG. Humanização da assistência ao parto no Brasil: os muitos sentidos de um movimento. Cienc. saude coletiva. 2005;10(3):627-37.
6. Osava RH. Parto Humanizado: Importante mudança para a saúde. Nursing. 2003;57(6):10-1.

7. Brasil. Lei n. 11.108, de 7 de abril de 2005. Dispõem sobre alteração da Lei no 8.080, de 19 de setembro de 1990, para garantir às parturientes o direito à presença de acompanhante durante o trabalho de parto, parto e pós-parto imediato, no âmbito do Sistema Único de Saúde - SUS. Diário Oficial da União. Disponível em: http://www.senado.gov.br/sf/publicacoes/diarios/pdf/ sf/2005/12/05122005.pdf

8. Carvalho MLM. Participação dos pais no nascimento em maternidade pública: dificuldades institucionais e motivações dos casais. Cad. saude publica. 2003;19 Suppl 2:S389-98.

9. Curitiba. Secretaria Municipal da Saúde. Programa Mãe Curitibana: Pré-Natal, Parto, Puerpério e a Atenção ao Recém-nascido. 2005.

10. Ministério da Saúde (BR). Conselho Nacional de Saúde. Diretrizes e normas regulamentadoras de pesquisa envolvendo seres humanos. Resolução n. 196, de 10 de outubro de 1996. Brasília; 1996.

11. Ministério da Saúde (BR). Manual dos Comitês de Mortalidade Materna. Secretaria de Atenção à Saúde. $3^{\mathrm{a}}$ ed. Brasília: Ministério da Saúde, 2007.

12. Santos JO, Zaguine AC, Machado B, Silva KR, Assenço M, Silva SR. Conhecimento de gestantes atendidas em Unidades Básicas de Saúde sobre o direito à presença do acompanhante durante o trabalho de parto. Rev. inst. ciênc. saúde. 2008; 26(3):294-8.

13. Instituto Brasileiro de Geografia e Estatística.[Internet] Ministério do Planejamento, Orçamento e Gestão. 2007. Disponível em: http://www.ibge.gov.br/home

14. Organização Mundial da Saúde (OMS). Assistência ao parto normal: um guia prático. Maternidade segura. Genebra, 1996.

15. Ministério da Saúde (BR). Secretaria de Atenção à Saúde. Departamento de Ações Programáticas Estratégicas. Área Técnica de Saúde da Mulher. Prénatal e Puerpério: atenção qualificada e humanizada - manual técnico/Ministério da Saúde, Secretaria de Atenção à Saúde, Departamento de Ações Programáticas Estratégicas - Brasília: Ministério da Saúde, 2005.

16. Diniz, SG. Gênero, saúde materna e o paradoxo perinatal. Rev. bras. crescimento desenvolv. hum. 2009;19(2):31326. 
17. Ministério da Saúde (BR). Programa de Humanização do Parto: humanização no pré-natal e nascimento. Brasília; 2002.

18. Nakano MAS, Silva LA, Beleza ACS, Stefanello J, Gomes FA. O suporte durante o processo de parturição: a visão do acompanhante. Acta paul. enferm. 2007; 20(2):131-7.

19. Oliveira ASS, Rodrigues DP, Guedes MVC, Felipe GF, Galiza FT, Monteiro LC. O acompanhante no momento do trabalho de parto e parto: percepção de puérperas. Cogitare enferm. 2011;16 (2):247-53.

20. Hotimsky, SN. Alvarenga, AT. A definição do acompanhante no parto: uma questão ideológica? Estudos feministas. 2002;2:461-81. 